\title{
Spatial Analysis of Rice Blast in China at Three Different Scales
}

\author{
Fangfang Guo, Xinglong Chen, Minghong Lu, Li Yang, Shiwei Wang, and Bo Ming $\mathrm{Wu}^{\dagger}$
}

First, second, fourth, fifth, and sixth authors: Department of Plant Pathology, China Agricultural University, Beijing, 100193, China; and third author: National Agricultural Technology Extension and Service Center, Ministry of Agriculture of the People's Republic of China, Beijing, 100125, China.

Accepted for publication 18 May 2018.

\begin{abstract}
In this study, spatial analyses were conducted at three different scales to better understand the epidemiology of rice blast, a major rice disease caused by Magnaporthe oryzae. At the regional scale, across the major rice production regions in China, rice blast incidence was monitored on 101 dates at 193 stations from 10 June to 10 September during 2009 to 2014, and surveyed in 143 fields in September 2016; at the county scale, three surveys were done covering one to five counties in 2015 to 2016; and, at the field scale, blast was evaluated in six fields in 2015 to 2016. Spatial cluster and hot spot analyses were conducted in the geographic information system on the

geographical pattern of the disease at regional scale, and geostatistical analysis was performed at all three scales. Cluster and hot spot analyses revealed that high-disease areas were clustered in mountainous areas in China. Geostatistical analyses detected spatial dependence of blast incidence with influence ranges of 399 to $1,080 \mathrm{~km}$ at regional scale and 5 to $10 \mathrm{~m}$ at field scale but not at county scale. The spatial patterns at different scales might be determined by inherent properties of rice blast and environmental driving forces, and findings from this study provide helpful information to sampling and management of rice blast.
\end{abstract}

Rice (Oryza sativa L.) is one of the top three food crops in China and feeds approximately one-half of the global population (Hossain and Fischer 1995). Although sustainably high yield of rice is critical for food security worldwide, sustainable production of rice is threatened by several important diseases (Zeigler and Savary 2009; Zeigler et al. 1994). Among them, rice blast caused by Magnaporthe oryzae (Couch and Kohn 2002) is one of the most important and widely distributed diseases across global rice-producing regions (Oerke 2006; Oerke et al. 1994; Ou 1985; Savary et al. 2000b). It also ranks as the second most important disease of rice in China, where the annual yield losses caused by rice blast was estimated 445,900 tons even though, annually, more than 10 thousand tons of fungicides were applied for controlling this disease on an acreage of $1.227-1.715 \times 10^{7} \mathrm{hm}^{2}$ during 2006 to 2015 (Liu et al. 2016). The pathogen can infect leaves, nodes, panicles, grains, and leaf sheath of rice under field conditions (Ou 1985). Among them, leaf blast and panicle blast are two of economic significance (Ding et al. 1999; Shen and Lin 1994). Leaf blast mainly affects the photosynthesis of rice plants and reduces carbohydrate supply (Bastiaans 1993), usually resulting in 1 to $10 \%$ yield losses (Savary et al. 2000a); however, in severe leaf blast epidemics, numerous lesions may occur on a leaf, leading to leaf death or plants at the early stages completely killed (Ou 1985). Panicle blast can reduce yield from the panicle, mainly by reducing grain filling, particularly when it occurred at or near the neck (or base) of a panicle, which can result in the break and loss of the whole head or panicle; therefore, it is usually more important economically (Zeigler et al. 1994).

To develop better strategies for management of rice blast, intensive efforts have been made to understand the epidemiology of

†Corresponding author: Bo Ming Wu; E-mail: bmwu@cau.edu.cn

Funding: This research is supported by the National Key Research and Develop Program of China (number 2016YFD0300702) and National Natural Science Foundation of China (number 31471727).

*The $\boldsymbol{e}$-Xtra logo stands for "electronic extra" and indicates that four supplementary figures and four supplementary tables are published online.

(C) 2018 The American Phytopathological Society this disease during the last decades (El Refaei 1977; Greer and Webster 2001; Kato and Kozaka 1974; Luo et al. 1998; Ou 1985; Peng et al. 2016; Suzuki 1975; Teng et al. 1991; Zeigler et al. 1994); however, several important aspects remained unclear. First, it has long been known that the primary inoculum sources of this disease include infested seed (Long et al. 2001), infested residues (FaivreRampant et al. 2013), and secondary hosts (Akase and Kusaba 2017; Du et al. 1997) but the finding on root infection of rice plants by this fungus suggested that soilborne inoculum might not be excluded from the potential primary inoculum sources (Sesma and Osbourn 2004). It remains unknown whether the fungus can overwinter in soil and, if so, what roles the soilborne inoculum has in epidemics of this disease in different rice production regions such as Northeast China, where winter is cold, and south of the Yangtze River, where winter temperature is moderate or warm. Second, rice blast fungus can produce numerous conidia, which were reported to be transported by wind over a distance from $1 \mathrm{~m}$ to $1 \mathrm{~km}$ (Ishiguro et al. 2001; Kingsolver et al. 1984; Ou 1985; Suzuki 1975; Urashima et al. 2007; van den Bosch et al. 1988; Zeigler et al. 1994) in rice fields, depending on wind velocity; meanwhile, the pathogen can also be seedborne and, potentially, soilborne (Guerber and TeBeest 2006; Sesma and Osbourn 2004; Wilson and Talbot 2009); however, it remains unclear what roles the different means have in disease spread and how far rice blast fungus can be transported (Saleh et al. 2014; Tharreau et al. 2009). These two questions are essential to understanding the epidemiology of rice blast and very important to management of this disease but it is difficult to answer these questions through direct field experiments due to the complexity of interactions among host, pathogen, and environment in this disease system.

Spatial pattern analysis of plant diseases is a useful tool with which to look for clues to the epidemiology of the diseases. Different primary inoculum sources and all those environmental conditions affecting epidemics of rice blast such as soil moisture, air temperature, and more have their intrinsic spatial patterns. The spatial pattern of a disease is the result of combined effects of primary inoculum sources, disease spread means, and environmental conditions (Burdon et al. 1989; Campbell and Noe 1985; Real and McElhany 1996). Knowledge of spatial patterns of diseased plants is not only very useful for better strategies in disease 
sampling (Lin et al. 1979) but also the time-varied spatial pattern of diseased plants reflects the initial inoculum pattern and the mechanisms of inoculum dispersal (Madden and Hughes 1995; Ristaino et al. 1993; Turechek and McRoberts 2013; Van de Lande and Zadoks 1999), providing a clue to the possible primary inoculum sources, the major means of disease spread in the field, and the critical environmental factors affecting the epidemics of the disease, which ultimately help to improve our strategies for disease monitoring (reduce sampling error) and disease management (Ristaino and Gumpertz 2000).

Many methods have been applied in analysis of spatial patterns in plant disease, which have been reviewed thoroughly (Campbell and Noe 1985; Madden and Hughes 1995; Wu and Subbarao 2005). Among them, geostatistical techniques, originally developed for the study of geological phenomena, have been widely used in characterizing the spatial patterns of plant diseases and pathogens (Chellemi et al. 1988; Dandurand et al. 1995; Horvath et al. 2007; Lannou and Savary 1991; Savary et al. 2001) and identifying possible factors involved in an epidemic (Byamukama et al. 2014; Freitas et al. 2016). Geostatistical methods are based on regionalized variables theory, which assumes that the difference between samples is merely a function of the distance between them and, therefore, these methods are not bound by the stringent requirements of stationarity compared with spatial autocorrelation (Isaaks and Srivastava 1989). The difference is often expressed as semivariance and plotted against the distance between samples, called lag distance, either in a specific direction or omnidirectionally, in an experimental semivariogram (Burrough and McDonnell 1998). Different models such as the spherical model can be fitted to this relationship, and parameters of sill, range, nugget can be estimated to characterize the spatial dependence, in which the proportion of structural variance (PSV) is often used to reflect the strength of spatial dependence (Horvath et al. 2007), and the influence range is usually the average size of clusters or the extent of the spatial dependence.

Hot spot analysis, based on the Getis-Ord $G_{i}^{*}$, is a useful tool for determining the local spatial dependence among neighboring observations (Ord and Getis 1995), which is different from other methods for global (overall average) spatial dependence (Getis and Ord 1992). At present, hot spot analysis has rarely been used in analyzing spatial patterns of plant disease (Skelsey et al. 2016), although it has been widely used in epidemiology of human diseases for finding high- and low-risk areas (Bhunia et al. 2013; McEntee and Ogneva-Himmelberger 2008; Patterson et al. 2017).

The Geographic Information System (GIS) has offered a platform for integrating geographic information, meteorological data, plant disease data, and social infrastructure systems into one system, which is vital for analyzing relationships between progress of plant disease and the determining environmental factors that would not otherwise be obvious (Nelson et al. 1999; Savary et al. 2011, 2012). Geostatistical analysis, hot spot analysis, and other statistical and modeling analyses can all be carried out in GIS. Increasingly, GIS's powerful spatial analysis tools have made it useful in plant disease epidemiology research (Byamukama et al. 2014; Graham et al. 2004; Margosian et al. 2009; Wu et al. 2001; Yuen and Mila 2015).

Thus far, there have been some reports on the spatial distribution of rice blast in China and in other rice production regions of the world. Most spatial analyses of rice blast were done in a single field or on the county scale (Chiang and Huang 2005; Greer and Webster 2001; Ishiguro et al. 2001; Peng et al. 2016; Rao et al. 2007). Some studies at large scale (country or world scale) were based on the simulation instead of field observations. For example, Luo et al. (1998) simulated the area under the disease progress curve (AUDPC) of leaf blast in five Asian countries (Japan, Korea, China, Thailand, and Philippines) based on weather data generated by WGEN and WMAK and mapped the geographical distribution with GIS, and Savary et al. (2012) simulated potential epidemics of leaf blast using model EPIRICE based on weather data extracted from the NASA
POWER agroclimatology dataset. As an example of a few studies on real field observation data at a large scale, Chen et al. (2014) classified the main rice-producing areas in China into high-, moderate-, and low (blast)-risk regions based on intensity and acreage of rice blast occurrence in 2000 to 2009 at 153 rice blast monitoring stations. Thus far, survey data at a large scale was limited, and studies on spatial distribution of this disease at different scales are lacking.

In this study, rice blast incidence data were obtained at three different scales - field scale (within individual fields), county scale (covering one to several counties), and regional scale (across multiple provinces) - in China and analyzed using GIS and its spatial analysis tools, including semivariogram and hot spot analysis procedures. The objectives of this study were to (i) determine the geographical pattern of rice (leaf and panicle) blast risk in China and (ii) analyze the spatial dependence of rice blast incidence at field scale, county scale, and regional scale.

\section{MATERIALS AND METHODS}

Study area and collection of disease data. For the regionalscale study, the study area covered most of the rice production areas in China and consisted of two separated regions: (i) region $\mathrm{A}$ included Northeast China single early-maturing rice-cropping region and (ii) region B included five subregions: South China double ricecropping region, Central and East China double and single ricecropping region, Southwest Plateau single and double rice-cropping region, Sichuan-Shaanxi Basin single rice-cropping region, and a small part of North China single rice-cropping region (Fig. 1) (Mei et al. 1988). During the period of 2009 to 2014, 193 representative county stations ( 33 in region $\mathrm{A}$ and 160 in region $\mathrm{B}$ ) were selected across these rice production areas. A rice field with a history of frequent blast occurrence was chosen at each selected station and planted with a local susceptible rice cultivar. The fields were managed according to common agricultural practices, except that no chemicals were applied to control rice blast. In each field, five sample sites were diagonally selected, and 10 hills of rice plants per site were monitored for leaf blast and panicle blast by staff at Plant Protection Stations of County Agricultural Bureaus following the guidance of the national standard (Standard Press of China 2009). All of the leaves (from rice seedlings turning green after transplanting to initial heading) or panicles (from initial heading to the early dough stage) in the selected hills were assessed. For each panicle, if any parts of it, either branches or the "neck", exhibited typical symptoms of blast, then it was classified as diseased. Incidence of leaf blast or panicle blast was recorded at each station. Due to change (removal and addition) of stations, differences in rice growing periods among stations, and other reasons, disease monitoring was done at only some stations on each of the 101 dates. The number of stations with disease monitoring data varied from 47 to 107 in region B and 0 to 28 in region A (Supplementary Table S1). Given the different cropping systems adapted and dates of planting, on each monitoring date, either leaf or panicle incidence was recorded depending on the locations, particularly in region $\mathrm{B}$, where several different cropping systems have been adapted. The data were a mixture of leaf and panicle blast, with more leaf blast early in the year and more panicle blast late in the year.

Due to an inadequate number of stations with monitoring data, the rice blast data from region A was not used for semivariogram analysis, and a separate data set obtained from field surveys on 12 to 29 September 2016 was used for semivariogram analysis of rice blast in region A (Supplementary Fig. S1). Close to the maturity stage, 143 rice fields in Northeast China were arbitrarily selected during a field trip. Longitude and latitude coordinates of the fields were measured with a global positioning system receiver (Magellan eXplorist 510; Magellan System Corp., San Dimas, CA). In each field, 100 heads were randomly selected and evaluated for panicle blast. Rice heads showing panicle blast symptoms (on primary 
branches and panicle axis) were counted and then incidence was calculated and recorded together with the geographic coordinates.

For the county-scale study, three surveys were conducted in south Jiangxi Province and the conjunction areas of Jiangxi, Anhui, and Hubei Provinces from 2015 to 2016 (Supplementary Fig. S2). In survey 1, 53 rice fields in Poyang County, Jiangxi Province and adjacent Dongzhi County, Anhui Province (the maximum distance between fields was approximately $124 \mathrm{~km}$ and the average nearest distance between fields was approximately $3.1 \mathrm{~km}$ ) were surveyed in October 2015. In survey 2, 151 rice fields in Wan'an County, Jiangxi Province (the maximum distance between fields was approximately $29 \mathrm{~km}$ and the average nearest distance was approximately $320 \mathrm{~m}$ ) were surveyed in early July 2016. In survey 3, 142 rice fields in several counties at the junction of Jiangxi, Hubei, and Anhui Provinces (the maximum distance between fields was approximately $173 \mathrm{~km}$ and the average nearest distance was approximately $2 \mathrm{~km}$ ) were surveyed in October 2016. Fields were selected arbitrarily during the field trips and their longitude and latitude coordinates measured with a portable GPS receiver. In total, 100 panicles at two to five randomly selected sites were evaluated for blast in each selected field, and incidence of panicle blast (on primary branches and panicle axis) was recorded.

For the field-scale study, evaluation of rice plants for panicle blast was done within individual fields. In 2015, three rice fields in Liaoning Province (fields A and B in Panjin City and field C in
Donggang City) were surveyed at the dough stage (Supplementary Fig. S3). Fifty panicles were assessed for panicle blast incidence on 33-by-17 and 31-by-17 grids ( 1 by $1 \mathrm{~m}$ ) in fields A and B, respectively, and on 16-by-22 grids ( 2 by $2 \mathrm{~m}$ ) in field C (Supplementary Fig. S4). In 2016, three rice fields in Jiangxi Province, field D in Wuyuan County, and fields E and F in Wan'an County were surveyed at the dough stage. In total, 25 panicles were assessed for panicle blast on 15-by-16 grids ( 1 by $1 \mathrm{~m}$ ) in field $\mathrm{D}$, on 16-by-23 grids $(1$ by $1 \mathrm{~m})$ in field $\mathrm{E}$, and on 15 -by-15 grids $(1.5$ by $1 \mathrm{~m})$ in field $\mathrm{F}$.

Geographical pattern of rice blast incidence at the regional scale. The geographical pattern of rice blast disease at the regional scale was analyzed in GIS software ArcGIS (ArcGIS 10.3; Environmental Systems Research Institute, Redlands, CA). First, a point coverage was generated from the latitude and longitude coordinates of the county stations for each survey date from 10 June to 10 September annually. Then, the latitude and longitude coordinates of the fields were transformed into plane coordinates using a Universal Transverse Mercator (UTM) projection. The plane coordinates of stations were used in the subsequent interpolation to generate a grid for rice blast incidence on each date. Due to various reasons, disease data were missing at some stations on some dates. If, on any date, monitoring data were available only for fewer than 12 stations in region $\mathrm{A}$ (fewer than 12 stations in region $\mathrm{A}$ had monitoring data on 21 of 101 dates and 47 or more stations in

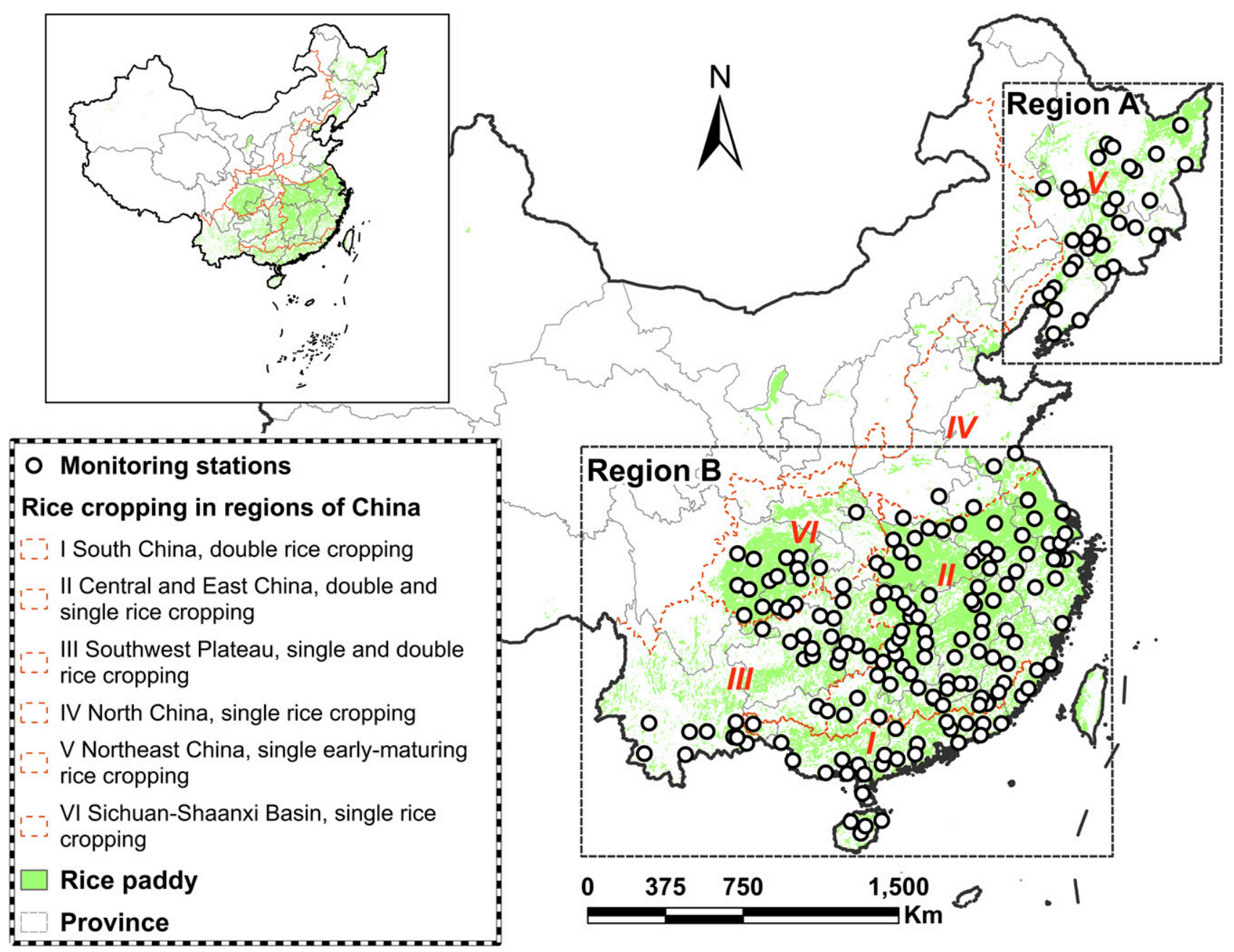

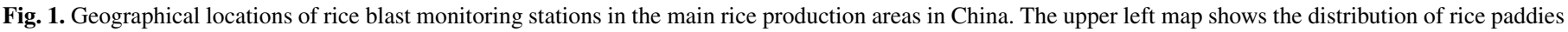

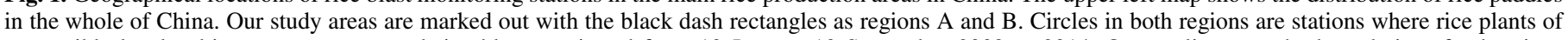

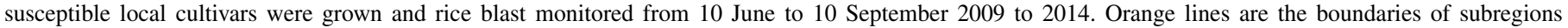
modified from the regionalization by Mei et al. (1988). 
region $\mathrm{B}$ had monitoring data on all 101 dates), then the data on that date were excluded for interpolation and subsequent analyses. Kriging is not suitable for interpolation in region A because it is difficult to fit a model to semivariogram when fewer than 30 stations had monitoring data available on each survey date. Given that the inverse distance weighted (IDW) method is applicable to interpolation with small number of data points (Rhodes 1993; Tomczak 1998), we used the IDW method with a minimum of 12 neighboring stations and a power of 2 for the interpolation of rice blast incidence in both regions. Considering no data in the large area between regions $\mathrm{A}$ and $\mathrm{B}$, all the projections, interpolations, and subsequent analyses were conducted separately for these two regions. Yearly AUDPC (Madden et al. 2007) were calculated from the grids of interpolated incidence on different dates during the year using trapezoid method, and an overall average grid was calculated from the six yearly AUDPC grids. To give equal weight to each yearly AUDPC in cluster analysis, each grid of yearly rice blast AUDPC in region $\mathrm{A}$ and region $\mathrm{B}$ was normalized separately via grid computing to make all of the 12 AUDPC grids have a mean of 0 and standard deviation of 1 (Wu et al. 2001). Cluster analysis was then conducted on the stack of the six yearly AUDPC grids in each of the two regions using two classes with low and high disease. This was conducted using the tool of "Iso Cluster Unsupervised Classification" in ArcGIS. Next, the resulting grids of the average rice blast AUDPC and low- or high-disease classes were overlapped with a grid of rice lands to remove areas that were not rice lands. The grid of rice lands was extracted from land-use grids derived from a remote sensing surveillance dataset for Land-Use and Land-Cover Change of China in 2015 provided by the Data Center for Resources and Environmental Sciences, Chinese Academy of Sciences (http:// www.resdc.cn). A grid was first generated by setting the value of a cell to 1 when the cell was for paddy land in the land-use grid (resolution $1 \mathrm{~km}$ ) and to 0 when it was for any other category of land use. The resulting grid was smoothed using the FOCAL average function in the GIS spatial analyst toolbox with a moving window of 5 by 5 cells; then, any cells with a value not smaller than 0.08 were considered as rice land (giving them a value of 1) and the other cells were set as no data.

Hot spot analyses of rice blast incidence at regional scale. The average rice (leaf and panicle) blast incidence was first calculated from all available data from 10 June 2009 to 10 September 2014 for each station, after which hot spot analyses were conducted in ArcGIS. The first step was to create a point coverage based on coordinates of all stations, with the average incidence as an attribute. After UTM projection, the method of $k$ nearest neighbors ( $k$ was set as $4,8,12$, and 20) and fixed distance (with threshold distances of 130, 200, $223910 \mathrm{~m}, 250,290,400$, and 1,000 km and the distance of $223,910 \mathrm{~m}$ as the nearest value where each station has at least one neighbor.) were used to generate spatial weight matrices (Environmental Systems Research Institute 2014a,b). The resulting spatial weight matrices were used to perform hotspot analysis (Environmental Systems Research Institute 2016a) on the point coverage to calculated Getis-Ord $G_{i}^{*}$ statistics for the average incidence at each station. For the distances used in hot spot analysis with fixed distance, Global Moran's I spatial autocorrelation test (Environmental Systems Research Institute 2016b,c) was also conducted to see if spatial dependence existed at those distances. Finally, the stations were classified into different categories according to their $\mathrm{Z}$ scores of $G_{i}^{*}$ statistics and mapped on a background map of China.

Semivariogram analysis of rice blast incidence at the regional, county, and field scales. At regional and county scales, geostatistical analysis was performed on rice blast disease incidence and associated spatial locations (longitude and latitude coordinates) using ArcGIS 10.3 (Johnston et al. 2001). First, the latitude and longitude coordinates of the fields were transformed into plane coordinates with a UTM projection. The projected data were first exported and first-order trends ( $x$ [longitude] and $y$ [latitude]) or second-order trends $\left(x y, x^{2}\right.$, and $\left.y^{2}\right)$ of rice blast incidence were examined using the Regression Procedure in SAS 9.4 (SAS Institute Inc., Cary, NC). If any systematical trend in disease incidence was detected, detrending was conducted via subtracting the predicted values (according to the fitted trend) from the original incidence (de Smith et al. 2015). Semivariogram analysis was then performed on original rice blast incidence or on the residuals when a significant trend was detected. A spherical model was fitted to the omnidirectional semivariogram and the model parameters, influence range $\mathrm{R}$, nugget $\mathrm{C} 0$, and partial sill $\mathrm{C} 1$ were estimated for each semivariogram. The PSV was also calculated as $\mathrm{C} 1 /(\mathrm{C} 0+\mathrm{C} 1)$.

At field scale, trends along $x$ and $y$ were first examined in the SAS program and the systematic trend was removed as described above if it was statistically significant. The data were then input into Surfer 13 (Golden Software, Golden, CO) to perform semivariogram analysis. Variance of moving window averages (Wu et al. 2006), which is similar to quadrat analysis (Turechek and McRoberts 2013) but two dimensional, was applied to analyze the spatial patterns at field scale as a comparison.

\section{RESULTS}

Geographical pattern of rice blast risk in China. The interpolated grids of rice (leaf and panicle) blast incidence on individual dates showed that, early in the season, rice blast incidence usually increased first in South China, such as Guangdong, Guangxi, the south end of Fujian, and Sichuan-Shaanxi Basin (summarized in Fig. 2; maps for individual dates not shown). By the end of June to early July, the high-disease foci were usually located in Southwest China (plateau and basin), hilly areas along the Yangtze River in Central and East China, and some small areas in South China (Fig. 2; maps for individual dates not shown). In August, high blast areas were mainly concentrated in the Southwest Plateau and Sichuan-Shaanxi Basin, continuing into the end of August and early September (Fig. 2; maps for individual dates not shown). Rice blast incidence in South China and SichuanShaanxi Basin often reached its first peak by the end of June and had a second peak toward Septembers (Fig. 2; maps for individual dates not shown). Rice blast incidence in East China often started from early June and peaked from the end of June to early July (Fig. 2; maps for individual dates not shown). Rice blast incidence in Southwest Plateau and Northeast China both had one peak, and the

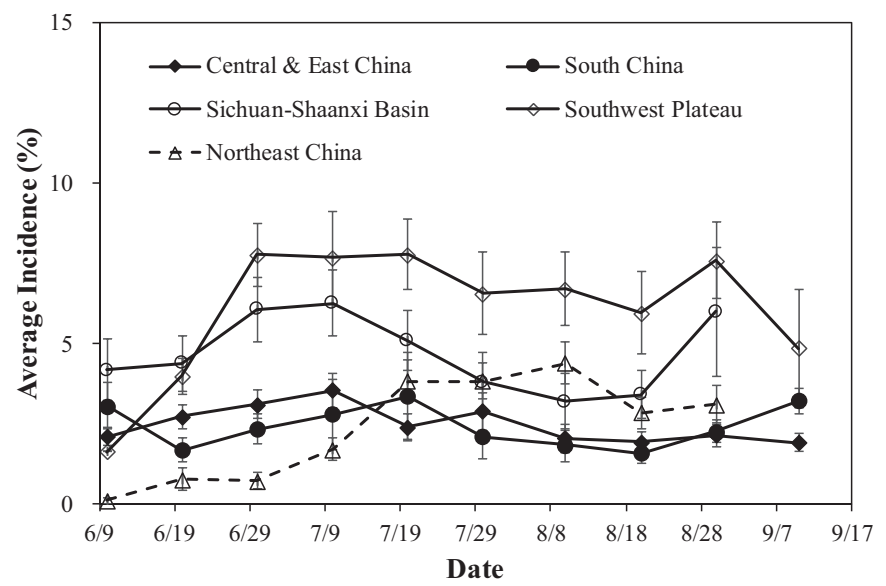

Fig. 2. Temporal progress of rice (leaf and panicle) blast incidence during the rice growing period from 10 June to 10 September in major rice production regions in China: Central and East China, South China, Sichuan and Shaanxi Basin, Southwest Plateau, and Northeast China. Each point was the mean of 25 to 271 incidence data at multiple stations from 2009 to 2014, and the vertical bars represent the standard errors of the means. 
peak was much higher and lasted longer in Southwest than in Northeast China (Fig. 2; maps for individual dates not shown). Overall, rice blast incidence was much higher in Southwest China than in the other areas.

The distribution of yearly AUDPC of leaf and panicle blast in region A varied greatly from year to year during the 6 years of this study, and the AUDPC of rice blast was always lower in region A than in region B (Supplementary Table S2; Fig. 3A to L). The grids of yearly AUDPC showed that the high-disease areas in region B varied from year to year (Fig. 3G to L). In 2009 (Fig. 3G), two major high-risk foci existed in Southwest China (Sichuan-Shaanxi Basin and the Southwest Plateau) and Southeast China, centered in Fujian Province, the expanded southward to Northeast Guangdong and northward to the junction areas of Zhejiang, Anhui, and Jiangxi Provinces. In 2010 (Fig. 3H) and 2011 (Fig. 3I), the high-disease areas were distributed similarly to those in 2009, with lower intensities around Sichuan-Shaanxi Basin and the Southwest Plateau, but the southeast high-disease region was larger than that in 2009 and divided into two parts: the northern focus was located in Central China, starting from the junction of Zhejiang, Fujian, Jiangxi, and Anhui, and extended northwestward to the south of Henan Province and the northeast of Hubei Province; and the southern focus was located in South China around the junction of Jiangxi, Guangdong, and Fujian Provinces. In 2012 (Fig. 3J), 2013 (Fig. 3K), and 2014 (Fig. 3L), the high rice blast areas were distributed similarly to those in 2010 except that (i) the high-disease focus in South China can hardly be seen in the 3 years, (ii) the high-disease focus in Central China hilly areas was larger and had higher AUDPC in the 3 years, and (iii) AUDPC of rice blast in Southwest China was low in 2013 and 2014 but very high in 2012. Even though the distribution of high-risk areas changed temporally, the average of yearly AUDPC (Fig. 4A) and results of cluster analysis (Supplementary Table S3; Fig. 4B) revealed that the high-risk areas in region B mainly included (i) Southwest China (high-altitude areas on the Southwest Plateau and hilly areas in Sichuan, Chongqing, west of Hunan, and west of Guangxi); (ii) the hilly areas in the central China from the junction of Jiangxi, Anhui, and Zhejiang to the junction of Hubei and Henan Provinces; and (iii) the junction area along the border of Jiangxi, Fujian, and Guangdong in South China. Although average of yearly AUDPC of rice blast varied little in region A (Fig. 4A), cluster analysis in region $\mathrm{A}$ identified some local high-disease areas, mainly including the area around Panjin City in Liaoning Province, the central and west of Jilin Province, and the northeast of Harbin City in Heilongjiang Province (Fig. 4B).

Hot spot analysis of rice blast. The results of hot spot analysis were affected by the methods used, and a clear separation of hot and cold spots was achieved when the fixed distance method was used with a distance threshold of $250 \mathrm{~km}$ or the method of $k$ nearest neighbors used with $k=8$ and 12 . Because the results from these three settings were similar and Global Moran's I autocorrelation test also revealed a strong spatial dependence of approximately $250 \mathrm{~km}$ (data not shown), only the results using a fixed-distance method with a distance threshold of $250 \mathrm{~km}$ were presented here (Fig. 4C). The results from hot spot analysis of rice (leaf and panicle) blast incidence revealed that the hot spots and cold spots were often aggregated in space (Fig. 4C). Similar to highdisease areas identified by cluster analysis with some differences, the hot spots of rice blast were concentrated in a few areas in region B: (i) Southwest China, mainly including the conjunction areas of Yunnan and Guangxi and hilly areas around Sichuan-Shaanxi Basin; and (ii) hilly areas in Central China, covering south Henan Province and west Anhui Province, which was slightly smaller than that from cluster analysis. However, the stations in high-disease areas identified in South China by cluster analysis were neither significantly hot nor significantly cold. Cold spots were concentrated in Hunan and Jiangxi Provinces. All stations in other areas
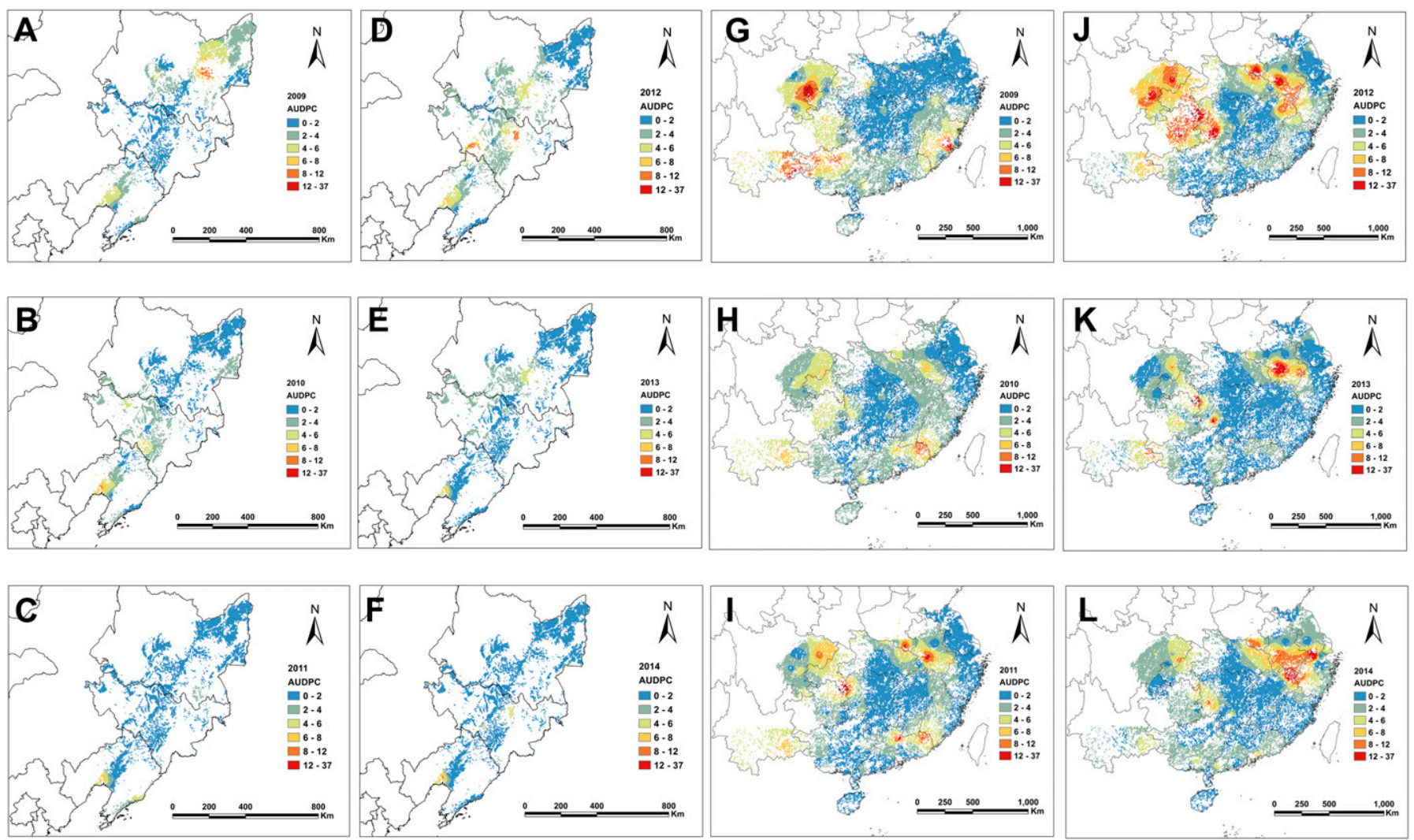

Fig. 3. Yearly area under disease or incidence progress curve (AUDPC) from 10 June to 10 September of rice (leaf and panicle) blast in 2009 to 2014 for A to F, region A and $\mathbf{G}$ to $\mathbf{L}$, region B of China. Interpolation of incidence was done using the inverse distance weight method, and AUDPC was calculated on interpolated incidence grids using the trapezoid method. 
(such as Northeast China) were classified as neutral spots where blast incidence was neither significantly lower nor significantly higher than those at their neighboring stations.

Semivariograms of rice blast incidence. At the regional scale, the rice (panicle) blast incidence from the surveys in region A (Northeast China) didn't show any significant systemic trend; however, a significant spatial dependence was detected by geostatistical analysis within an influence range of $560 \mathrm{~km}$ (Table 1; Fig. 5A; Supplementary Table S4). The rice (leaf and panicle) blast incidence in region $\mathrm{B}$ exhibited a significant first- or second-order trend on 27 of the 101 dates during this study (Table 1), including a trend of higher incidence in the west than in the east along the longitude direction on 15 dates (expressed as $-x,-x^{2}$, or $[x-2.055 \times$ $\left.10^{7}\right]^{2}$ in Table 1 , where $x$ in the range of $1.825 \times 10^{7}$ to $2.053 \times 10^{7}$ ), lower in the middle and higher in west and east along the longitude direction on 10 August 2010 (expressed as $\left[x-1.997 \times 10^{7}\right]^{2}$ in Table 1), higher in the north than in the south along the latitude direction on five dates (expressed as $+y$ or $+y^{2}$ in Table 1), lower in the southwest than in the northeast on three dates (+xy in Table 1), higher in the southwest than in the northeast on 5 September 2013 and 10 June 2014 ( $-x y$ in Table 1), and higher in the northwest than in the southeast on 15 August $2012(-x,+y$ in Table 1). Among the total 27 semivariograms obtained after detrending, 4 semivariograms exhibited significant spatial dependence (statistically significant $R^{2}$ for model). Usually, the semivariograms did not change much before and after detrending, both showing no spatial dependence (Fig. 5B) or significant spatial dependence (Fig. 5C). On some dates, however, the semivariance increased with distance, showing spatial dependence before the systemic trend was removed, but no significant spatial dependence was detected after detrending (Fig. 5D). These semivariograms could be fitted to the spherical model with an influence range between 399 and $1,080 \mathrm{~km}$ (Table 1; Fig. 5C). Among the other 74 survey dates with no systemic trend, six semivariograms of rice blast incidence exhibited significant spatial dependence with an influence range between 421 and
$1,015 \mathrm{~km}$ (Table 1). Interestingly, among those 10 semivariograms with a strong spatial dependence, 8 were in 2010 but only 1 occurred in 2011 and another in 2014 (Table 1).

At the county scale, rice panicle blast incidence in survey 1 and survey 2 had a significant linear trend along the east-to-west direction, decreasing from west to east (Table 2). No significant

TABLE 1. Results of semivariogram analysis on rice (leaf and panicle) blast incidence at the regional scale

\begin{tabular}{|c|c|c|c|}
\hline \multirow[b]{2}{*}{ Trend detected ${ }^{\mathrm{b}}$} & \multirow[b]{2}{*}{$\begin{array}{c}\text { Survey or } \\
\text { monitoring dates }\end{array}$} & \multicolumn{2}{|c|}{$\begin{array}{c}\text { Parameters of } \\
\text { spherical model }^{\mathrm{a}}\end{array}$} \\
\hline & & $\begin{array}{c}\text { Range } \\
(\mathrm{km})\end{array}$ & $\begin{array}{l}\text { Average } \\
\text { PSV }^{\mathrm{c}}\end{array}$ \\
\hline \multicolumn{4}{|l|}{ Region A } \\
\hline None & $\begin{array}{l}\text { Field surveys, } \\
\text { September } 2016\end{array}$ & 560 & 0.77 \\
\hline \multicolumn{4}{|l|}{ Region B } \\
\hline None & 68 dates & NS & NA \\
\hline None & 6 dates & $421-1,015$ & 0.70 \\
\hline$-x$ or $-x^{2}$ & 12 dates & NS & NA \\
\hline$-\left(x-2.055 \times 10^{7}\right)^{2}$ & 24 July 2010 & NS & NA \\
\hline$-x$ & $\begin{array}{l}15 \text { and } 20 \text { August } \\
2010\end{array}$ & 399 and 960 & 0.64 \\
\hline$-\left(x-1.997 \times 10^{7}\right)^{2}$ & 10 August 2010 & 1,080 & 1.00 \\
\hline$+y,+y^{2}$ & 4 dates & NS & NA \\
\hline$+y$ & 15 August 2011 & 803 & 0.51 \\
\hline$+x y$ & 3 dates & NS & NA \\
\hline$-x y$ & $\begin{array}{l}5 \text { September 2013, } \\
\text { 10 June } 2014\end{array}$ & NS & NA \\
\hline$-x,+y$ & 15 August 2012 & NS & NA \\
\hline
\end{tabular}

a Parameters of the spherical model fitted to the variograms; NA $=$ not available and NS $=$ not statistically significant at $\alpha=0.05$.

b Symbols: $x=$ longitude, in the range of $1.825 \times 10^{7}$ to $2.053 \times 10^{7} \mathrm{~m}$ (after Universal Transverse Mercator projection), and $y=$ latitude.

c Average of proportion of structural variance $(\mathrm{PSV})=\mathrm{C} 1 /(\mathrm{C} 0+\mathrm{C} 1)$, where $\mathrm{C} 0$ is the nugget and $\mathrm{C} 1$ is the partial sill of the spherical model.
A

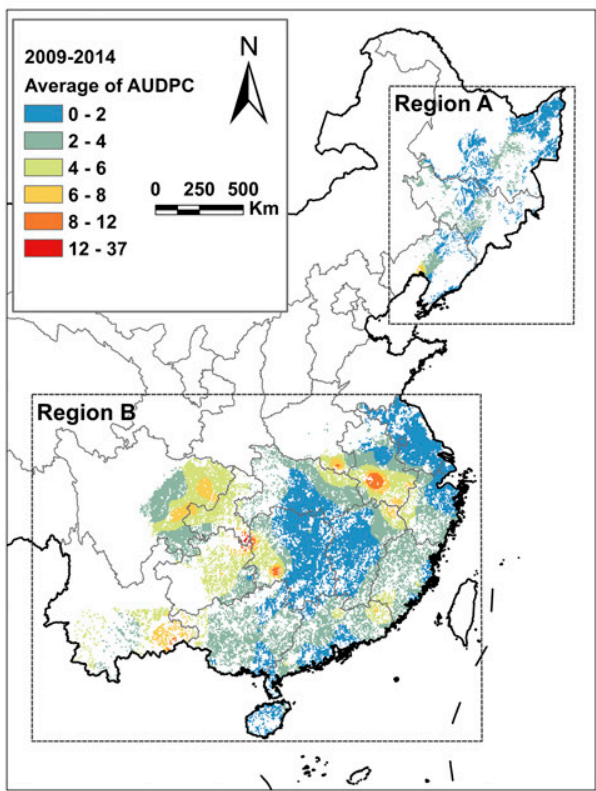

B

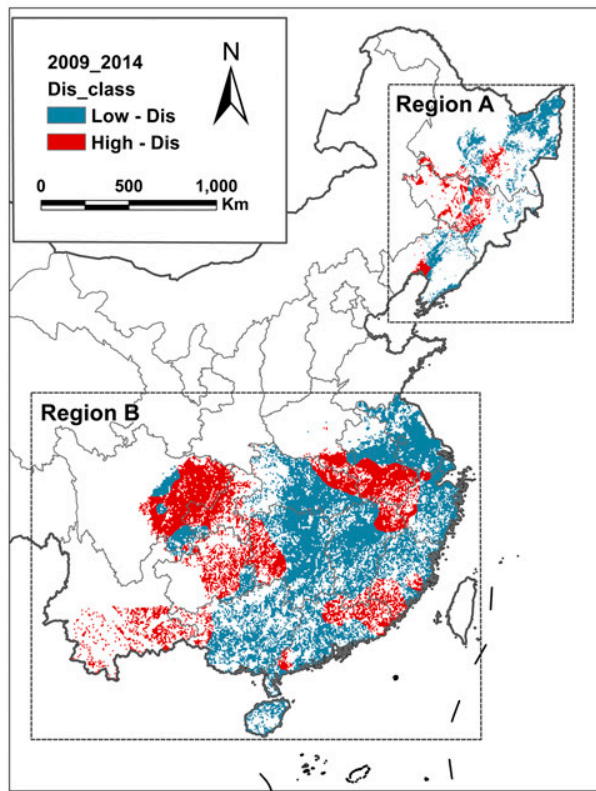

C

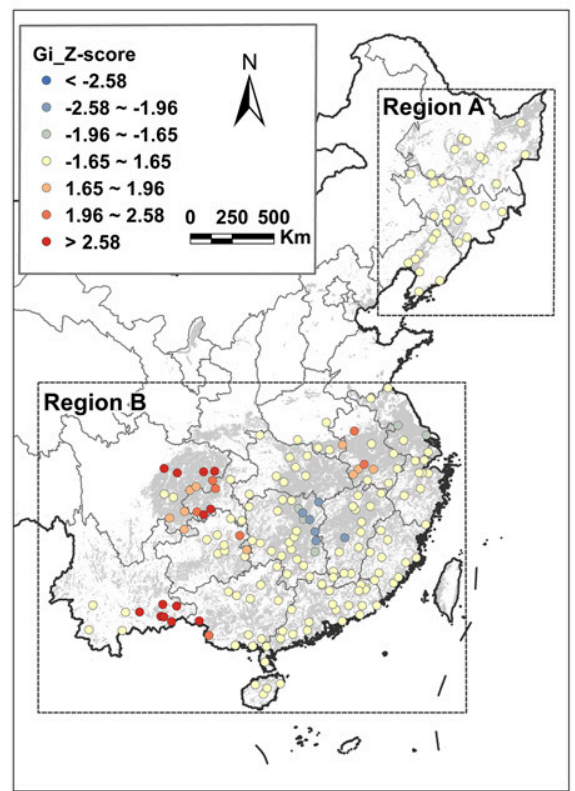

Fig. 4. Geographical distribution of rice (leaf and panicle) blast in China at the regional scale. A, Average of yearly area under the disease progress curve (AUDPC) of rice blast in 2009 to 2014; interpolation of blast incidence for region A and region B were done separately using the inverse distance weight method, and AUDPC and their averages were calculated from interpolated incidence. B, Results of cluster analysis on normalized yearly AUDPC of rice blast in 2009 to 2014; normalization and cluster analysis were also done separately for regions A and B. C, Results of hot spot analysis based on average rice blast incidence from 2009 to 2014. Gi_Z-scores are Getis-Ord Gi* statistics expressed as standard deviation, and critical values of $\pm 2.58, \pm 1.96$, and \pm 1.65 correspond to significance levels $0.01,0.05$, and 0.10 , respectively. Stations are hot spots (positive $Z$ scores) or cold spots (negative $Z$ scores) when their Getis-Ord Gi* statistics are statistically significant. 
spatial dependence of rice blast incidence was detected after detrending in these two areas, nor in survey 3 without detrending (Fig. 5E).

At the field scale, no systemic trend was significant in field D and a strong spatial dependence was detected for rice panicle blast

A
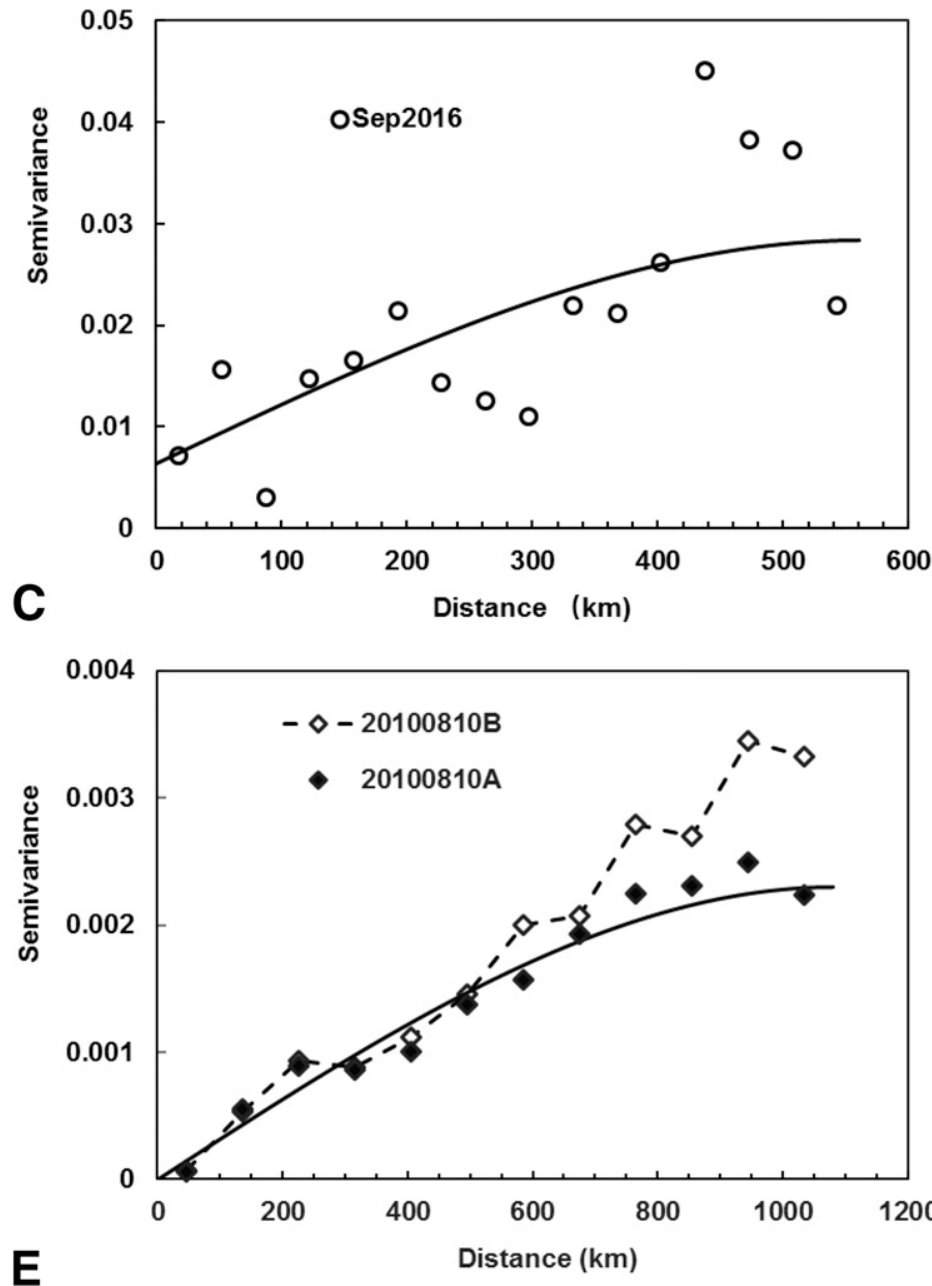

$\mathbf{E}$

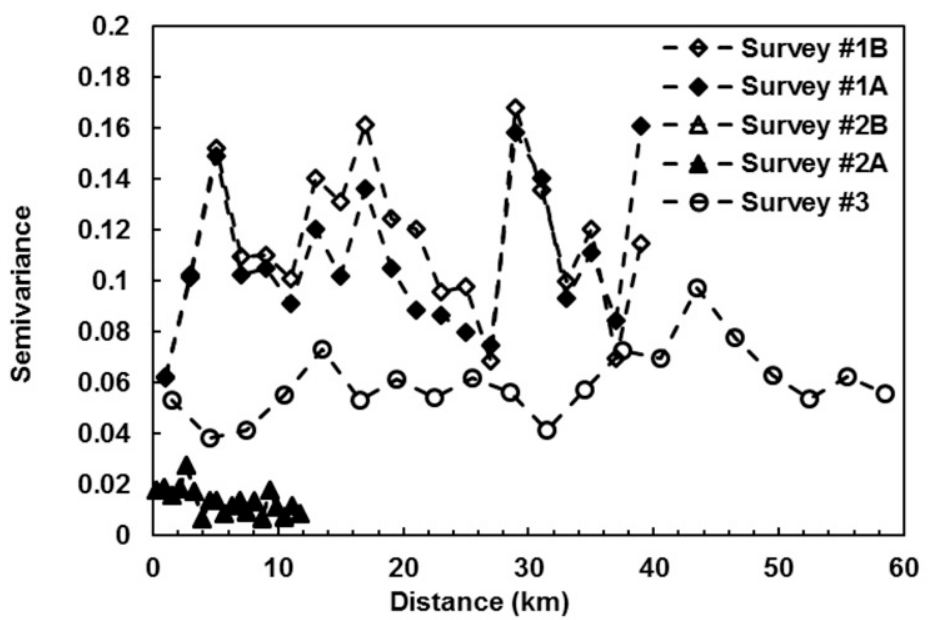

incidence, with an influence range of $5.00 \mathrm{~m}$ (Table 3). A significant systemic trend was detected in fields A, B, C, E, and F (Table 3). After removal of these systemic trends, semivariograms of rice blast incidence in fields A, B, and C in Northeast China exhibited a strong spatial dependence, with an influence range of 7.20 to $10.00 \mathrm{~m}$

B
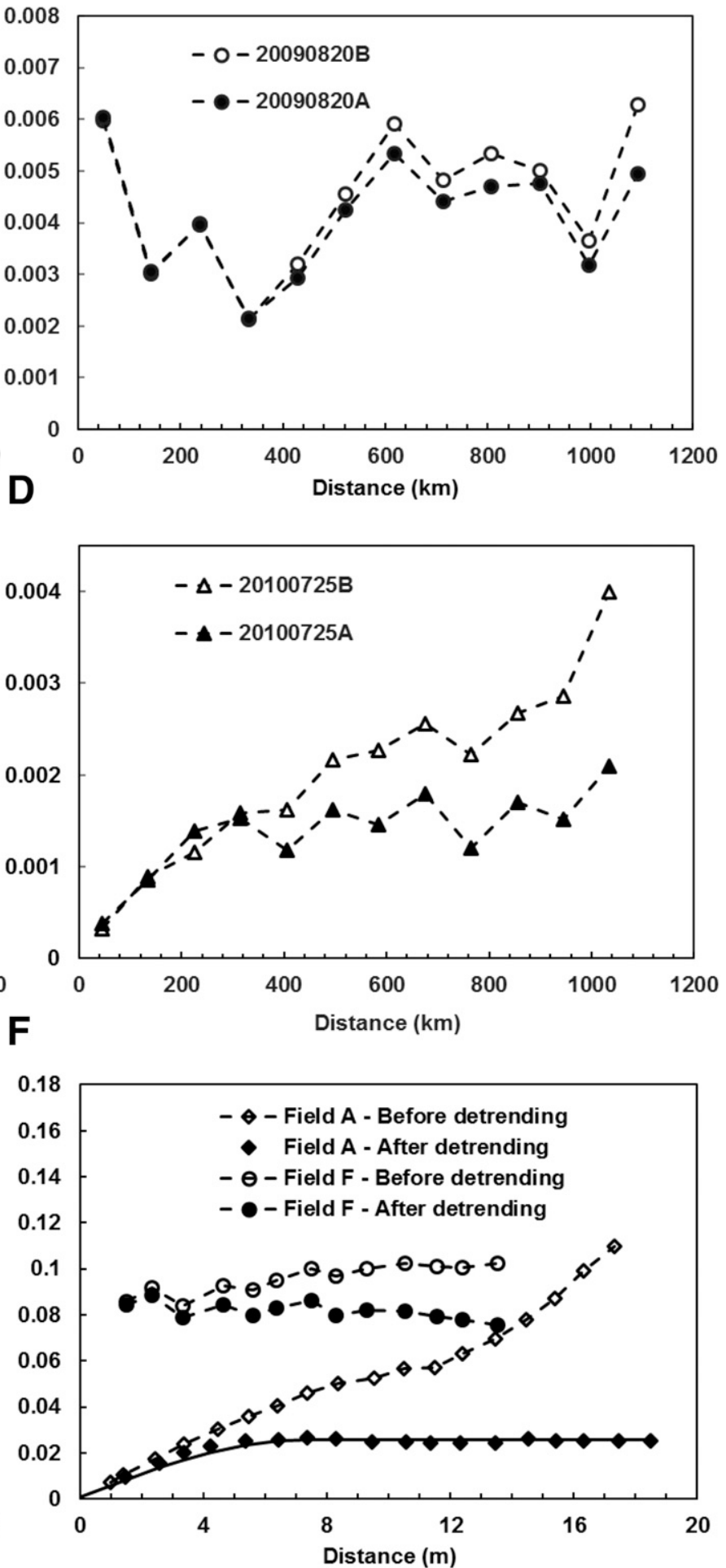

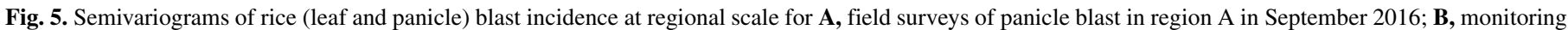

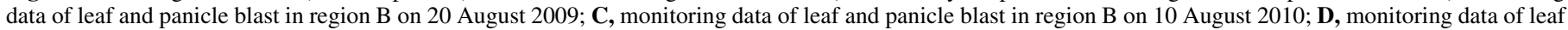

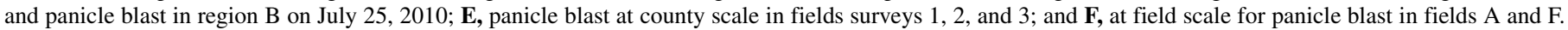

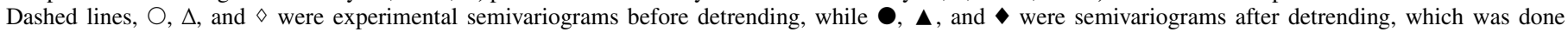

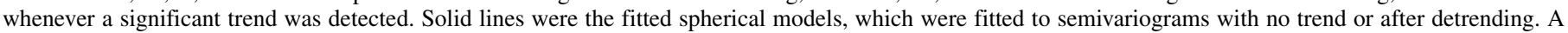

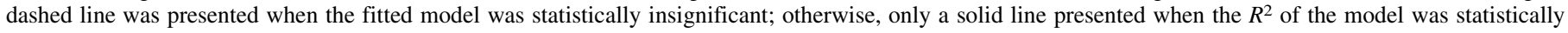
significant. 
(Table 3; Fig. 5F, example of field A) but no significant spatial dependence was detected in fields $\mathrm{E}$ and $\mathrm{F}$ (Table 3; Fig. 5F, example of field F). Similar to the results from geostatistical analysis but slightly different, the result from variance of moving window averages revealed that the panicle blast was aggregated in fields A, B, C, D, and E within 2-by-2 and 3-by-3 windows but might not have been in field $\mathrm{F}$, where the aggregation index was relatively small (Fig. 6). The maximum window size with a positive aggregation index was larger in fields $\mathrm{A}, \mathrm{B}$, and $\mathrm{C}$ than in fields $\mathrm{D}$ and $\mathrm{E}$ (Fig. 6).

\section{DISCUSSION}

This study, for the first time, analyzed the geographical distribution of rice blast at regional scale across the major rice production areas in China. Because fields with disease history were chosen, local susceptible cultivars were planted, and no fungicide was applied for rice blast at all county stations, the results based on the monitoring data in this study might have overestimated the risk of rice blast; however, the overestimates were consistent over all stations and, therefore, the relative geographical distribution could still represent the potential risk faced in commercial fields. Both map cluster analysis and average of yearly AUDPC demonstrated that the high rice blast risk mainly concentrated in (i) Southwest China, mainly including high-altitude areas on the Southwest Plateau and hilly areas in Sichuan, Chongqing, and west Hunan; (ii) hilly areas in Central China, from the junction of Anhui, Jiangxi, and Zhejiang Provinces to the junction of Henan and Hubei Provinces; (iii) the hilly areas in South China and the junction areas along the border of Jiangxi, Fujian, and Guangdong; and (iv) some local areas in Northeast China, including a small area near Panjin in Liaoning Province, the central and west Jilin Province, and the northeast of Harbin City in Heilongjiang Province. Hot spot analysis also provided similar results, with some minor differences. These results were partly in agreement with those from the previous simulation studies based on weather conditions (Luo et al. 1998; Savary et al. 2012), although comparison in specific local rice production areas of China could not be made due to the difficulty in retrieving high-resolution data from the published maps. Our results were consistent with the previous reports on local distribution of rice blast; for example, Peng et al. (1995) found that severity of rice blast in Fuling, Chongqing depended strongly on altitude; it was often low in the low-altitude areas $(<500 \mathrm{~m})$, high for both leaf and neck blast in the middle-altitude areas (500 to $1,000 \mathrm{~m}$ ), and high for neck blast in the high-altitude areas (>1,000 m). Suzuki (1975) also found that the disease was influenced by topographic factors: incidence and intensity of blast increased from plains areas to areas along the foot of a mountain and areas between mountains. The high rice blast disease in mountainous and hilly areas might have resulted from conditions conducive to rice blast. In hilly and mountainous areas of the tropical and subtropical zone, the temperature decreases with altitude and, in most of these areas, precipitation increases with altitude; there is much shorter sunshine duration and solar radiation than in plains areas; and there is higher relative humidity and dew at night in lowlands and valleys (Cui 1995). It was reported that low night temperature, which is a characteristic of high-altitude areas, led to a partial breakdown of resistance (Manibhushanrao and Day 1972), and shorter solar radiation, frequent heavy fog, and prolonged dew are conducive to rice blast (Peng et al. 2016; Suzuki 1975; Venkatarao and Muralidharan 1982). Temperature and dew also have effects on rice blast fungus infection and lesion development and sporulation (Calvero 1994; Kato and Kozaka 1974; Pinnschmidt et al. 1995). The geographical pattern of rice

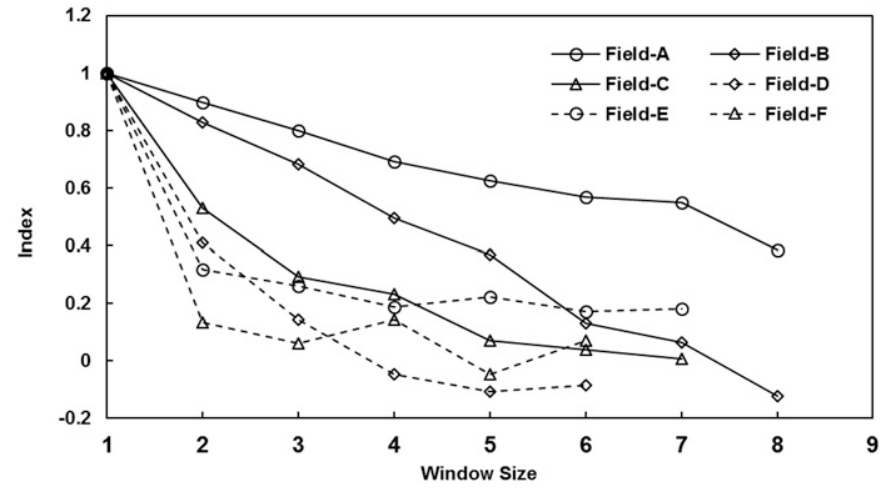

Fig. 6. Aggregation index of rice blast incidence for field scale surveys in fields $\mathrm{A}$ to $\mathrm{F}$, calculated using the variance of moving window average method at window sizes from 1 by 1 to 8 by 8 . A positive index suggested aggregation, a value of zero suggested random, and negative values suggested uniform or overdispersion.

TABLE 2. Results of semivariogram analysis on rice panicle blast incidence at county scale

\begin{tabular}{lccccccc}
\hline & & \multicolumn{3}{c}{ Spherical models fitted to the semivariograms } \\
\cline { 3 - 7 } Surveys & Trends detected $^{\mathrm{a}}$ & Lag size $(\mathrm{m})$ & Nugget & Range $(\mathrm{m})$ & Partial sill & $R^{2}$ & PSV $^{\mathrm{b}}$ \\
\hline 1 & $-0.00001135 x+232.91$ & 2,000 & 0.024 & 4,331 & 0.085 & 0.083 & 0.78 \\
2 & $-0.00000244 x+49.61$ & 600 & 0.014 & 12,000 & 0.000 & 0.001 & 0.00 \\
3 & None & 3,000 & 0.045 & 47,125 & 0.022 & 0.250 & 0.33 \\
\hline
\end{tabular}

a Symbol: $x=$ longitude.

b Proportion of structural variance $(\mathrm{PSV})=\mathrm{C} 1 /(\mathrm{C} 0+\mathrm{C} 1)$, where $\mathrm{C} 0$ is the nugget and $\mathrm{C} 1$ is the partial sill of the spherical model.

TABLE 3. Results of semivariogram analysis on rice panicle blast incidence within individual fields

\begin{tabular}{|c|c|c|c|c|c|c|c|}
\hline \multirow[b]{2}{*}{ Fields } & \multirow[b]{2}{*}{ Trends detected ${ }^{\mathrm{b}}$} & \multirow[b]{2}{*}{ Lag size $(\mathrm{m})$} & \multicolumn{5}{|c|}{ Spherical models fitted to the semivariograms ${ }^{a}$} \\
\hline & & & Nugget & Range (m) & Partial sill & $R^{2}$ & $\mathrm{PSV}^{\mathrm{c}}$ \\
\hline A & $-0.0029 x^{2}+0.0485 x+0.0007 x y-0.0011 y^{2}+0.0101 y+0.57$ & 1.00 & 0.001 & 7.20 & 0.0245 & 0.850 & 0.96 \\
\hline B & $-0.0003 x^{2}-0.0002 y^{2}+0.0085 x+0.0099 y+0.01$ & 0.83 & 0.000 & 8.25 & 0.0343 & 0.993 & 1.00 \\
\hline $\mathrm{D}$ & None & 0.57 & 0.010 & 5.00 & 0.1000 & 0.890 & 0.91 \\
\hline E & $0.0011 x y+0.30$ & 1.00 & $\ldots$ & $\ldots$ & $\ldots$ & $\ldots$ & $\ldots$ \\
\hline $\mathrm{F}$ & $-0.0066 x+0.16$ & 1.00 & $\ldots$ & $\ldots$ & $\ldots$ & $\ldots$ & $\ldots$ \\
\hline
\end{tabular}

a Data in bold indicate that the fitted spherical model is statistically significant at $\alpha=0.05$.

b Symbols: $x$ and $y$ were coordinates along west to east and south to north, in meters.

c Proportion of structural variance $(\mathrm{PSV})=\mathrm{C} 1 /(\mathrm{C} 0+\mathrm{C} 1)$, where $\mathrm{C} 0$ is the nugget and $\mathrm{C} 1$ is the partial sill of the spherical model 
blast risk in China provides a clue for the possible factors affecting epidemics of rice blast. It would be worthwhile to make further efforts to clarify the roles of different factors in epidemic of rice blast. The risk map is also helpful for making better use of our resource in management of rice blast, by allowing us to focus our attention, fungicides, and other resources on small areas with high risk.

To our knowledge, this was the first work that systematically analyzed the epidemics of rice blast disease at three different scales from within individual paddy fields to over large regions across multiple provinces. In the past, most spatial analyses of rice blast disease incidence were done in a single field or within a local area covering a few counties (Chiang and Huang 2005; Greer and Webster 2001; Ishiguro et al. 2001; Peng et al. 2016; Rao et al. 2007). One of the interesting findings of this study was that the incidence of rice blast exhibited systemic trends at three different scales, and a strong spatial dependence at field and regional scales. At regional scale, the rice blast incidence occasionally had a clustered spatial pattern in region B during this study period. The influence range, or the largest size of clusters, ranged from 399 to $1,080 \mathrm{~km}$. Although the spatial dependence of rice blast in Northeast China was not analyzed in the same period due to inadequate data points, spatial dependence of rice blast was also confirmed in a separate field survey (fields were selected differently than was done for monitoring in region B) in September 2016, where the cluster size was found to be approximately $560 \mathrm{~km}$. Different from the findings at regional scale, no spatial dependence was significant for rice blast incidence at county scale. Rice blast incidence was also aggregated at field scale in four of six fields we surveyed.

The possible processes behind the spatial patterns of rice blast generally include dispersal of pathogen, spatial patterns of rice plants of susceptible varieties (Kim 1987), and environmental heterogeneity such as wind (Lambert et al. 1980). Among them, evidence from multiple research reports (Mohapatra et al. 1997; Rao et al. 2007) suggested that the aggregation of rice blast within individual fields, where the host plants and environmental conditions were usually distributed uniformly, was due to the dispersal of pathogen inoculum, most likely airborne conidia, which were trapped at a distance of $16 \mathrm{~m}$ windward of a neighboring disease outbreak field and as far as $32 \mathrm{~m}$ leeward of a neighboring field (Suzuki 1975); it might less likely have resulted from aggregated inoculum in the soil that survived from the previous crops (Campbell and Noe 1985; Sesma and Osbourn 2004). The relatively small clusters of rice blast incidence at field scale were consistent with the previous reports in that the spores of rice blast fungus were found to disperse over a short distance of $4 \mathrm{~m}$ (van den Bosch et al. 1988) or 1 to $5 \mathrm{~m}$ (Tharreau et al. 2009), and the maximum dispersal distance could be within $230 \mathrm{~m}$ (Kingsolver et al. 1984; Zeigler et al. 1994) or $1 \mathrm{~km}$ from the inoculum source (Ishiguro et al. 2001; Urashima et al. 2007). The reasons for relatively larger clusters in Northeast China than in southern China (region B) in this study were as yet unknown. Because our surveys at field scale were exclusively focused on panicle blast in this study, the smaller clusters $(5 \mathrm{~m}$ or no clusters) in fields in southern China than in Northeast China $(7.2 \mathrm{~m}$ or larger clusters) might suggest lower wind velocity for spore dispersal, a shorter period of conducive weather conditions, or a shorter susceptible stage of rice plants for panicle blast in southern China than in Northeast China. For the three fields in Northeast China, rice plants started heading in August, when rainy days are common and provide a prolonged period with high moisture or low temperature conditions for infection by the blast pathogen (Agrometeorology Research Institute, Chinese Academy of Agricultural Sciences 1962); therefore, the disease may have a second or even third dispersal on susceptible cultivars. For the three fields surveyed in region B, rice plants started heading in June for the two fields in Wan'an County or in early August for the single crop rice in Wuyuan County, when the temperature was extremely high in both areas. This might have limited the time window with suitable conditions for the infection of panicles.
Another important driving force for the spatial distribution of rice blast might be the terrain, which affects microclimate (Huang 1986). As discussed above, hills, high altitude, and large variation in altitude may create a microclimate characterized with low night temperature, fog, frequent and long dew duration, and fewer sunshine hours, all of which are conducive to rice blast. In the rice production areas, these kinds of terrains are aggregated in space, therefore resulting in aggregation of rice blast incidence. For example, the high-altitude and hilly rice production areas in region $\mathrm{B}$ were consistent with the three high blast foci identified by cluster analysis. The size of clusters can be as large as the size of hilly areas or the flat areas enclosed between hilly areas. The aggregation of rice blast at regional scale across provinces was unlikely due to dispersal of the pathogen inoculum. This was partially confirmed by the findings of no strong spatial dependence at the county scale. The lack of spatial dependence at county scale but strong spatial dependence at field scale also suggested that long-distance dispersal of inoculum might not be important, other than causing sparse initial foci at a distance; and that local inoculum, which could be from infected seed or various pathogen structures surviving in soil, might have played important roles in the epidemics of rice (particularly panicle) blast in the major rice-producing areas of China.

The clustering of rice blast spatial patterns has important implications. First, due to the aggregated patterns of rice blast at a regional scale, the disease-monitoring nursery fields should be arranged in a way to reflect the variation in altitude and weather conditions, and to have fewer stations in a region with uniform conditions. Second, the aggregation at field scale suggested that, to have a good estimate of disease level in a field for disease forecast or yield loss assessment, a good sampling strategy is to sample more distant sites and few plants at each site but not to sample many plants from a few sites. The aggregated pattern at the regional scale and relatively stable high-disease risk areas over years will allow us to concentrate our resources (labor, equipment, and chemicals) within relatively small areas and, therefore, make better use of resources in disease management. The high-risk areas usually are hilly and mountainous areas, which are often located at the junction of several provinces or counties. Therefore, we should promote a professional pest control system for large-scale pest prevention, and promote regional cooperation.

\section{ACKNOWLEDGMENTS}

Data for base maps were provided by the Data Center for Resources and Environmental Sciences, Chinese Academy of Sciences. We thank M. Lu at ESRI China for help in data processing in GIS; and the staffs of Wan'an Plant Protection Stations, Liaoning Provincial Saline-Alkali Land Utilization and Research Institute, and Donggang Demo Reproduction Farm for their cooperation during our field surveys.

\section{LITERATURE CITED}

Agrometeorology Research Institute, Chinese Academy of Agricultural Sciences. 1962. Rice and Meteorology. China Agriculture Press, Beijing, China. (In Chinese)

Akase, K., and Kusaba, M. 2017. Overwintering of Pyricularia oryzae in wild infected foxtails. J. Gen. Plant Pathol. 83:197-204.

Bastiaans, L. 1993. Effects of leaf blast on growth and production of a rice crop. Neth. J. Plant Pathol. 99:323-334.

Bhunia, G. S., Kesari, S., Chatterjee, N., Kumar, V., and Das, P. 2013. Spatial and temporal variation and hotspot detection of kala-azar disease in Vaishali district (Bihar), India. BMC Infect. Dis. 13:64.

Burdon, J. J., Jarosz, A. M., and Kirby, G. C. 1989. Pattern and patchiness in plant-pathogen interactions-causes and consequences. Annu. Rev. Ecol. Syst. 20:119-136.

Burrough, P. A., and McDonnell, R. A. 1998. Principles of Geographical Information Systems. Oxford University Press, New York.

Byamukama, E., Eggenberger, S. K., Coelho-Netto, R. A., Robertson, A. E., and Nutter, F. W., Jr. 2014. Geospatial and temporal analyses of Bean pod mottle virus epidemics in soybean at three spatial scales. Phytopathology 104:365-378. 
Calvero, S. B., Jr. 1994. Developing Models to Predict Favorable Environments for Rice Blast. Master's thesis, Oregon State University, Corvallis, OR.

Campbell, C. L., and Noe, J. P. 1985. The spatial analysis of soilborne pathogens and root diseases. Annu. Rev. Phytopathol. 23:129-148.

Chellemi, D. O., Rohrbach, K. G., Yost, R. S., and Sonoda, R. M. 1988. Analysis of the spatial pattern of plant pathogens and disease plants using geostatistics. Phytopathology 78:221-226.

Chen, D., He, Z., Feng, C., Liu, W., Lu, M., and Xiang, Y. 2014. Study on the occurrence regionalization of rice major diseases. Southwest China J. Agric. Sci. 27:1072-1078.

Chiang, K. S., and Huang, Y. T. 2005. Analysis of the spatial pattern of rice leaf blast. Plant Prot. Bull. Taichung 47:129-142.

Couch, B. C., and Kohn, L. M. 2002. A multilocus gene genealogy concordant with host preference indicates segregation of a new species, Magnaporthe oryzae, from M. grisea. Mycologia 94:683-693.

Cui, D. 1995. Chinese Agroclimatology. Zhejiang Science and Technology Publishing House, Hangzhou, China.

Dandurand, L. M., Knudsen, G. R., and Schotzko, D. J. 1995. Quantification of Pythium ultimum var. sporangiiferum zoospore encystment pattern using geostatistics. Phytopathology 85:186-190.

de Smith, M. J., Goodchild, M. F., and Longley, P. A. 2015. Geospatial Analysis: A Comprehensive Guide to Principles, Techniques and Software Tools, 5th ed. The Winchelsea Press, Winchelsea, UK.

Ding, K., Tan, G., and Wu, J. 1999. A study on yield loss caused by rice blast. Acta Phytophylac. Sin. 26:60-64.

Du, X., Sun, S., Tao, R., Sun, G., and Zhang, Z. 1997. Effects of weed-host of Pyricularia on incidence of rice blast disease. Acta Phytopathol. Sin. 27: 327-332.

El Refaei, M. I. 1977. Epidemiology of Rice Blast Disease in the Tropics with Special Reference to the Leaf Wetness in Relation to Disease Development. Indian Agricultural Research Institute, New Delhi, India.

Environmental Systems Research Institute. 2014a. How hot spot analysis (Getis-Ord $\mathrm{Gi}^{*}$ ) works. Online publication. http://resources.arcgis.com/en/ help/main/10.2/005p/005p00000011000000.htm

Environmental Systems Research Institute. 2014b. Modeling spatial relationship. Online publication. http://resources.arcgis.com/en/help/main/10.2/ index.html\#//005p00000005000000\#GUID-729B3B01-6911-41E9-AA998A4CF74EEE27

Environmental Systems Research Institute. 2016a. Hot spot analysis (GetisOrd $\left.\mathrm{Gi}^{*}\right)$. Online publication. http://desktop.arcgis.com/en/arcmap/10.3/ tools/spatial-statistics-toolbox/hot-spot-analysis.htm

Environmental Systems Research Institute. 2016b. Spatial autocorrelation (Global Moran's I). Online publication. http://desktop.arcgis.com/en/arcmap/10.3/tools/spatial-statistics-toolbox/spatial-autocorrelation.htm.

Environmental Systems Research Institute. 2016c. Incremental spatial autocorrelation. Online publication. http://desktop.arcgis.com/en/arcmap/10.3/ tools/spatial-statistics-toolbox/incremental-spatial-autocorrelation.htm

Faivre-Rampant, O., Geniès, L., Piffanelli, P., and Tharreau, D. 2013. Transmission of rice blast from seeds to adult plants in a non-systemic way. Plant Pathol. 62:879-887.

Freitas, A. S., Pozza, E. A., Alves, M. C., Coelho, G., Rocha, H. S., and Pozza, A. A. A. 2016. Spatial distribution of yellow sigatoka leaf spot correlated with soil fertility and plant nutrition. Precis. Agric. 17:93-107.

Getis, A., and Ord, J. K. 1992. The analysis of spatial association by use of distance statistics. Geogr. Anal. 24:189-206.

Graham, A. J., Atkinson, P. M., and Danson, F. M. 2004. Spatial analysis for epidemiology. Acta Trop. 91:219-225.

Greer, C. A., and Webster, R. K. 2001. Occurrence, distribution, epidemiology, cultivar reaction, and management of rice blast disease in California. Plant Dis. 85:1096-1102.

Guerber, C., and TeBeest, D. O. 2006. Infection of rice seed grown in Arkansas by Pyricularia grisea and transmission to seedlings in the field. Plant Dis. 90:170-176.

Horvath, B. J., Kravchenko, A. N., Robertson, G. P., and Vargas, J. M., Jr. 2007. Geostatistics analysis of dollar spot epidemics occurring on a mixed sward of creeping bentgrass and annual bluegrass. Crop Sci. 47:1206-1216.

Hossain, M., and Fischer, K. S. 1995. Rice research for food security and sustainable agricultural development in Asia: Achievements and future challenges. GeoJournal 35:286-298.

Huang, S. 1986. Advances in the investigation of the topographical microclimate in China (sum up). Geogr. Res. 5:90-101.

Isaaks, E. H., and Srivastava, R. M. 1989. An Introduction to Applied Geostatistics. Oxford University Press, New York.

Ishiguro, K., Harasawa, R., and Kobayashi, T. 2001. Disease gradients from rice blast inoculum sources observed at the beginning of epidemics. (Abstr.) Phytopathology 91:S42.

Johnston, K., Ver Hoef, J. M., Krivoruchko, K., and Lucas, N. 2001. Using ArcGIS Geostatistical Analyst. Environmental Systems Research Institute, New York.
Kato, H., and Kozaka, T. 1974. Effect of temperature on lesion enlargement and sporulation of Pyricularia oryzae in rice leaves. Phytopathology 64: $828-830$

Kim, C. H. 1987. Disease dispersal gradients of rice blast from a point source. Korean J. Plant Pathol. 3:131-136.

Kingsolver, C. H., Barksdale, T. H., and Marchetti, M. A. 1984. Rice blast epidemiology. Penn. Agric. Exp. Stn. Bull. 853:1-33.

Lambert, D. H., Villareal, R. L., and Mackenzie, D. R. 1980. A general model for gradient analysis. J. Phytopathol. 98:150-154.

Lannou, C., and Savary, S. 1991. The spatial structure of spontaneous epidemics of different disease in a groundnut plot. Neth. J. Plant Pathol. 97: 355-368.

Lin, C. S., Poushinsky, G., and Mauer, M. 1979. An examination of five sampling methods under random and clustered disease distributions using simulation. Can. J. Plant Sci. 59:121-130.

Liu, W., Liu, Z., Huang, C., Lu, M., Liu, J., and Yang, Q. 2016. Statistics and analysis of crop yield losses caused by main diseases and insect pests in recent 10 years. Plant Prot. (China) 42:1-9.

Long, D. H., Correll, J. C., Lee, F. N., and TeBeest, D. O. 2001. Rice blast epidemics initiated by infested rice grain on the soil surface. Plant Dis. 85: 612-616.

Luo, Y., Teng, P. S., Fabellar, N. G., and TeBeest, D. O. 1998. The effects of global temperature change on rice leaf blast epidemic: A simulation study in three agroecological zones. Agric. Ecosyst. Environ. 68:187-196.

Madden, L. V., and Hughes, G. 1995. Plant disease incidence: Distributions, heterogeneity, and temporal analysis. Annu. Rev. Phytopathol. 33:529-564.

Madden, L. V., Hughes, G., and van den Bosch, F. 2007. The Study of Plant Disease Epidemics. The American Phytopathological Society, St. Paul, MN.

Manibhushanrao, K., and Day, P. R. 1972. Low night temperature and blast disease development on rice. Phytopathology 62:1005-1007.

Margosian, M. L., Garrett, K. A., Hutchinson, J. M. S., and With, K. A. 2009. Connectivity of the American agricultural landscape: Assessing the national risk of crop pest and disease spread. Bioscience 59:141-151.

McEntee, J. C., and Ogneva-Himmelberger, Y. 2008. Diesel particulate matter, lung cancer, and asthma incidences along major traffic corridors in MA, USA: A GIS analysis. Health Place 14:817-828.

Mei, F., Wu, X., Yao, C., and Li, L. 1988. Rice cropping regionalization in China. Chin. J. Rice Sci. 2:97-110.

Mohapatra, N. K., Mukherjee, A. K., Mishra, A. K., and Nayak, P. 1997. Dispersion statistics and sequential sampling plan for rice blast disease. Oryza 34:367-371.

Nelson, M. R., Orum, T. V., Jaime-Garcia, R., and Nadeem, A. 1999. Application of geographic information system and geostatistics in plant disease epidemiology and management. Plant Dis. 83:308-319.

Oerke, E. C. 2006. Crop losses to pests. J. Agric. Sci. 144:31-43.

Oerke, E. C., Dehne, H. W., Schönbeck, F., and Weber, A. 1994. Crop Production and Crop Protection: Estimated Losses in Major Food and Cash Crops. Elsevier Science, Amsterdam, The Netherlands.

Ord, J. K., and Getis, A. 1995. Local spatial autocorrelation statistics: Distributional issues and an application. Geogr. Anal. 27:286-306.

$\mathrm{Ou}$, S. H. 1985. Rice Diseases. CAB International Mycological Institute, Slough, UK

Patterson, B., Morrow, C. D., Kohls, D., Deignan, C., Ginsburg, S., and Wood, R. 2017. Mapping sites of high TB transmission risk: Integrating the shared air and social behavior of TB cases and adolescents in a South African township. Sci. Total Environ. 583:97-103.

Peng, C., Bai, T., Ding, P., Feng, L., and Yang, Y. 2016. Study on the occurrence and epidemic regularity and region division of rice blast in Nanchong City. Agric. Sci. Technol. 17:927-937.

Peng, H., Zhang, J., Rao, Z., Peng, S., and Wu, X. 1995. Investigations on rice blast in different ecological zones. Southwest China J. Agric. Sci. 8:59-64.

Pinnschmidt, H. O., Bonman, J. M., and Kranz, J. 1995. Lesion development and sporulation of rice blast. J. Plant Dis. Prot. 102:299-306.

Rao, A. V. S., Mukherjee, A. K., Mohapatra, N. K., and Nayak, P. 2007. Spatial distribution of rice blast disease under natural field epidemics. Res. J. Agric. Biol. Sci. 3:615-620.

Real, L. A., and McElhany, P. 1996. Spatial pattern and process in plantpathogen interactions. Ecology 77:1011-1025.

Rhodes, H. R. 1993. Multivariate and Geostatistical Analyses of Phase I Eastern Lake Survey Data. Ph.D. thesis, The University of Arizona, Tucson, AZ.

Ristaino, J. B., and Gumpertz, M. L. 2000. New frontiers in the study of dispersal and spatial analysis of epidemics caused by species in the genus Phytophthora. Annu. Rev. Phytopathol. 38:541-576.

Ristaino, J. B., Larkin, R. P., and Campbell, C. L. 1993. Spatial and temporal dynamics of Phytophthora epidemics in commercial bell pepper fields. Phytopathology 83:1312-1320.

Saleh, D., Milazzo, J. E., Adreit, H., Fournier, E., and Tharreau, D. 2014. South-East Asia is the center of origin, diversity and dispersion of the rice blast fungus, Magnaporthe oryzae. New Phytol. 201:1440-1456. 
Savary, S., Castilla, N. P., and Willocquet, L. 2001. Analysis of the spatiotemporal structure of rice sheath blight epidemics in a farmer's field. Plant Pathol. 50:53-68.

Savary, S., Nelson, A., Sparks, A. H., Willocquet, L., Duveiller, E., Mahuku, G., Forbes, G., Garrett, K. A., Hodson, D., and Padgham, J. 2011. International agricultural research tackling the effects of global and climate changes on plant diseases in the developing world. Plant Dis. 95:1204-1216.

Savary, S., Nelson, A., Willocquet, L., Pangga, I., and Aunario, J. 2012. Modeling and mapping potential epidemics of rice diseases globally. Crop Prot. 34:6-17.

Savary, S., Willocquet, L., Elazegui, F. A., Castilla, N. P., and Teng, P. S. 2000a. Rice pest constraints in tropical Asia: Quantification of yield losses due to rice pests in a range of production situations. Plant Dis. 84:357-369.

Savary, S., Willocquet, L., Elazegui, F. A., Teng, P. S., Du, P. V., Zhu, D., Tang, Q., Huang, S., Lin, X., Singh, H. M., and Srivastava, R. K. 2000 b. Rice pest constraints in tropical Asia: Characterization of injury profiles in relation to production situations. Plant Dis. 84:341-356.

Sesma, A., and Osbourn, A. E. 2004. The rice leaf blast pathogen undergoes developmental processes typical of root-infecting fungi. Nature 431: 582-586.

Shen, M., and Lin, J. Y. 1994. The economic impact of rice blast disease in China. Pages 321-331 in: Rice Blast Disease. R. S. Zeigler, S. A. Leong, and P. S. Teng, eds. CAB International in association with the International Rice Research Institute, Oxon, UK.

Skelsey, P., Elphinstone, J. G., Saddler, G. S., Wale, S. J., and Toth, I. K. 2016. Spatial analysis of blackleg-affected seed potato crops in Scotland. Plant Pathol. 65:570-576.

Standard Press of China. 2009. Rules of Investigation and Forecast of the Rice Blast [Pyricularia oryzae (Cavara)]. Standard Press of China, Beijing, China.

Suzuki, H. 1975. Meteorological factors in the epidemiology of rice blast. Annu. Rev. Phytopathol. 13:239-256.

Teng, P. S., Klein-Gebbinck, H. W., and Pinnschmidt, H. 1991. An analysis of the blast pathosystem to guide modeling and forecasting. Pages 1-30 in: Rice Blast Modeling and Forecasting: Selected Papers from the International Rice Research Conference, 27-31 August 1990 Seoul, Korea. International Rice Research Institute, Manila, Philippines.

Tharreau, D., Fudal, I., Andriantsimialona, D., Santoso, U. D., Fournier, E., Lebrun, M., and Nottéghem, J. 2009. World population structure and migration of the rice blast fungus, Magnaporthe oryzae. Pages 209-215 in: Advances in Genetics, Genomics and Control of Rice Blast Disease. G.-L.
Wang and B. Valent, eds. Springer Science \& Business Media B. V., Dordrecht, The Netherlands.

Tomczak, M. 1998. Spatial interpolation and its uncertainty using automated anisotropic inverse distance weighting (IDW)-cross-validation/jackknife approach. J. Geogr. Inf. Decis. Anal. 2:18-30.

Turechek, W. W., and McRoberts, N. 2013. Considerations of scale in the analysis of spatial pattern of plant disease epidemics. Annu. Rev. Phytopathol. 51:453-472.

Urashima, A. S., Leite, S. F., and Galbieri, R. 2007. Eficiência da disseminação aérea em Pyricularia grisea [Efficiency of aerial dissemination of Pyricularia grisea]. Summa Phytopathol. 33:275-279.

Van de Lande, H. L., and Zadoks, J. C. 1999. Spatial patterns of spear rot in oil palm plantations in Surinam. Plant Pathol. 48:189-201.

van den Bosch, F., Zadoks, J. C., and Metz, J. A. J. 1988. Focus expansion in plant disease. II: Realistic parameter-sparse models. Phytopathology 78: 59-64.

Venkatarao, G., and Muralidharan, K. 1982. Effect of meteorological conditions on the incidence and progress of blast disease on rice. J. Plant Dis. Prot. 89:219-223.

Wilson, R. A., and Talbot, N. J. 2009. Under pressure: Investigating the biology of plant infection by Magnaporthe oryzae. Nat. Rev. Microbiol. 7: 185-195.

Wu, B. M., and Subbarao, K. V. 2005. Analysis of spatial patterns in plant pathology. Pages 167-187 in: Recent Research Developments in Plant Pathology, 3. S. G. Pandalai, ed. Research Signpost, Kerala, India.

Wu, B. M., Subbarao, K. V., Ferrandino, F. J., and Hao, J. J. 2006. Spatial analysis based on variance of moving window average. J. Phytopathol. 154: 349-360.

Wu, B. M., van Bruggen, A. H. C., Subbarao, K. V., and Pennings, G. G. H. 2001. Spatial analysis of lettuce downy mildew using geostatistics and geographic information systems. Phytopathology 91:134-142.

Yuen, J., and Mila, A. 2015. Landscape-scale disease risk quantification and prediction. Annu. Rev. Phytopathol. 53:471-484.

Zeigler, R. S., Leong, S. A., and Teng, P. S., eds. 1994. Rice Blast Disease. $\mathrm{CAB}$ International in association with the International Rice Research Institute, Oxon, UK

Zeigler, R. S., and Savary, S. 2009. Plant diseases and the world's dependence on rice. Pages 3-9 in: The Role of Plant Pathology in Food Safety and Food Security. Plant Pathology in the 21st Century (Contributions to the 9th International Congress). R. N. Strange and M. Lodovica Gullino, eds. Springer, Dordrecht, The Netherlands. 